it is very far from being universally available. Its routine use for patients who cannot swallow should prevent the degrading spectacle of elderly, undernourished patients with their hands bandaged to the side of the bed-to prevent inadvertent removal of a nasogastric tube - in a usually fruitless attempt to support nutrition.

IAN FORGACS Consultant Physician

ANDREW MACPHERSON MRC Clinician Scientist CHRISTOPHER TIBBS Senior Registrar

Department of Gastroenterology,

King's College Hospital,

London SE22 8PT

1 Gauderer MWL, Ponsky JL, Izant RJ Jr. Gastrostomy without laparotomy: a percutaneous endoscopic technique. F Pediatr Surg 1980;15:872-5.
2 Ponsky JL, Gauderer MW, Stellato TA. Percutaneous endoscopic gastrostomy: a review of 150 cases. Arch Surg 1983;118:913-4

3 Kirby DF, Craig RM, Tsang T-K, Plotnick BH. Percutaneous endoscopic gastrostomies: a prospective evaluation and review of the literature. Fournal of Parenteral and Enteral Nutrition 198610:155-9.

4 Larson DE, Burton DD, Schroeder KW, DiMagno EP. Percutaneous endoscopic gastrostomy. Indications, success, complications and mortality in 314 consecutive patients. Gastroenterology 1987;93:48-52

5 Park RHR,'Allison MC, Lang J, Spence E, Morris AJ, Danesh BJZ, et al. Randomised comparison of percutaneous endoscopic gastrostomy and nasogastric tube feeding in patients with persisting neurological dysphagia. BMF 1992;304:1406-9.

6 Jones M, Santanello SA, Falcone RE. Percutaneous endoscopic versus surgical gastrostomy. fournal of Parenteral and Enteral Nutrition 1990;14:533-4.

McKay MD, Tedesco FJ. Percutaneous endoscopic gastrostomy. In: Bennett JR, Hunt RH, eds. Therapeutic endoscopy and radiology of the gut. 2nd ed. London: Chapman and Hall, 1990:207-14 8 Wicks C, Gimson A, Vlavianos P, Lombard M, Panos M, Macmathuma P, et al. Assessment of the percutaneous endoscopic gastrostomy feeding tube as part of an integrated approach to enteral feeding. Gut 1992;33:613-6.

9 Ciocon JO, Silverstone FA, Graver $M$, Foley $\mathrm{CJ}$. Tube feeding in elderly patients. Indications, benefits and complications. Arch Intern Med 1988;148:429-33.

10 Cogen R, Weinryb J. Aspiration pneumonia in nursing home patients fed via gastrostomy tubes. Am F Gastroenterol 1989;84:1509-12.

11 Grossman TW, Duncavage JA, Dennison B, Kay J, Toofill RJ. Complications associated with a narrow bore nasogastric tube. Am Otol Rhinol Laryngol 1984;93:460-3.

12 Benya R, Mobarhan S. Enteral alimentation: administration and complications. $\mathcal{J}$ Am Coll Nutr 1991;10:209-19.

\title{
Implementing the patient's charter in outpatient services
}

\section{Will require organisation, discipline, and perhaps more resources}

Meeting the rights and standards of the patient's charter ${ }^{1}$ will require radical changes in many parts of the health service, particularly in the conduct of outpatient practice in hospitals where the demand for outpatient services is high. "A clear explanation of any treatment proposed, including any risks and alternatives," takes time..$^{23}$ "A specific appointment time within 30 minutes of which the patient will be seen" takes organisation and discipline. Each specialty clinic will have to develop rigid booking patterns to reflect these needs.

An average of 20 minutes has been suggested as the time it takes to see each new patient referred to general surgical outpatients clinics; 10 minutes should be allocated for each follow up appointment. ${ }^{4}$ This time is required to take a history from and examine the patient, explain any treatment, make notes, complete data entry sheets, and dictate letters to referring doctors. Specialties will vary in how long it takes to provide a consultation of the requisite quality. In specialties without senior experienced deputies consultant clinics should be booked for no more than 44 weeks of the year to allow for consultants' annual and study leave, thereby reducing the need to cancel or rearrange clinics at short notice.

Outpatient practice should be structured around the need for a consultant's opinion. The number of patients followed up should fall: over two million such patients were seen in general surgical outpatient clinics in 1989, and many of these appointments were probably of doubtful benefit to the patients ${ }^{5}$ and unnecessary because general practitioners are willing and able to do much of this work. ${ }^{67} \mathrm{By}$ judicious use of indirect contact with patients by letter or telephone doctors can check the effects of their interventions without the patients having to attend the outpatient clinic and unnecessary use of scarce outpatient clinic time. ${ }^{8}$

Guidelines for referring patients from general practice can also lead to better use of clinic time. ${ }^{9}$ One such handbook for referral, the Somerset Pink Book, ${ }^{10}$ includes protocols for using open access endoscopy and diagnostic imaging facilities and advises general practitioners that certain patients may have a minor operation or special tests before or sometimes instead of an outpatient consultation.

Meeting the standards of the patient's charter will require not only time and organisation but also discipline. Generally, consultants are reluctant to refuse a request from another doctor to see a patient urgently or to expedite an appointment. Such patients can be accommodated without disruption only if an appropriate number of appointment times are left free. This is at the expense of routine patients, for whom the time from referral to appointment invariably lengthens further. This may be why the patient's charter omits to put a limit on the time between referral and the first outpatient appointment -a limit of 13 weeks had been confidently expected-and leaves it to local health authorities to implement. To meet this requirement hospital units would need not only to reorganise the provision of outpatient services within existing resources but also to identify the need for extra consultant teams.

After the injection of government funds to deal with long waiting lists for inpatient surgery the next target may be the long waits for outpatient consultation. Hospital units will be expected to formulate schemes to reduce these times. Calculating the extra resources needed will be helped by guidelines specific to individual specialties, such as those of the Royal College of Surgeons, which recommend that one consultant surgeon with a standard support team can see 1000 new referrals from general practitioners each year. ${ }^{11}$

Implementing the patient's charter may help to make explicit the gap between the level of service which is required by the purchasers and that which providers can offer. In specialties that are currently overwhelmed extra resources and consultants will be the only solution.

Medical Director, Taunton and Somerset Hospital

CHARLES COLLINS

Taunton, Somerset TA1 5DA

Department of Health. The patient's charter. London: HMSO, 1991.

2 Morell DC, Evans ME, Morris RW, Roland MO. The five minutes consultation: effect of time constraint on clinical content and patient satisfaction. $B M 7$ 1986;292:870-3.

Bishop F, Matthews FJ, Probert CSJ, Billet J, Battock T, Frisby SD, et al. Patients' views on how to run hospital outpatient clinics. I Soc Med 1991;84:522-3.

4 Collins CD. Model workload agreement for DGH general surgeon: discussion paper. Ann R Coll Surg Engl 1990;suppl 72:48-50.

5 Coggon D, Goldacre MJ. Outpatient follow-up after appendicectomy. Lancet 1976;i:1346-7.

6 Louden ISL. Outpatient follow-up. $\mathcal{F}$ C Coll Physicians Lond 1976;26:792-3.

7 McCormack TT, Collier JA, Abel PD, Collins CD, Ritchie WN. Attitudes to follow-up after uncomplicated surgery-hospital outpatients or general practitioners? Health Trends 1984;16: 46-7.

8 Kirk RM. Reducing outpatient attendances. BMF 1986;293:1521-2.

9 Emmanuel J, Walter N. Referrals from general practice to hospital outpatient departments: strategy for improvement. $B M 7$ 1989;299:722-4.

10 Rivett R. Somerset pink book. Taunton: Taunton and Somerset Postgraduate Medical Centre, 1991.

11 Royal College of Surgeons of England. General surgical workload and the provider/purchaser contract. London: RCS, 1990. 